\title{
Impact of HLA Diversity on Donor Selection in Organ and Stem Cell Transplantation
}

\author{
Jean-Marie Tiercy ${ }^{a}$ Frans Claas ${ }^{b}$ \\ ${ }^{a}$ National Reference Laboratory for Histocompatibility, Department of Genetics and Laboratory Medicine, and

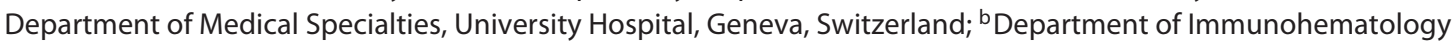 \\ and Blood Transfusion, Leiden University Medical Center, Leiden, The Netherlands
}

\section{Key Words}

HLA polymorphism · Kidney transplantation .

Hematopoietic stem cell transplantation · Haplotype

frequency · Alloreactivity - Epitopes

\begin{abstract}
The human major histocompatibility complex is a multigene system encoding polymorphic human leucocyte antigens $(H L A)$ that present peptides derived from pathogens to the immune system. The high diversity of HLA alleles and haplotypes in the worldwide populations represents a major barrier to organ and allogeneic hematopoietic stem cell transplantation, because HLA incompatibilities are efficiently recognized by $T$ and B lymphocytes. In organ transplantation, pre-transplant anti-HLA antibodies need to be taken into account for organ allocation. Although HLA-incompatible transplants can be performed thanks to immunosuppressive drugs, the de novo production of anti-HLA antibodies still represents a major cause of graft failure. The HLAMatchmaker computer algorithm determines the immunogenicity of HLA mismatches and allows to define HLA antigens that will not induce an antibody response. Because of the much higher stringency of HLA compatibility criteria in stem cell trans-
\end{abstract}

plantation, the best donor is a HLA genotypically identical sibling. However, more than $50 \%$ of the transplants are now performed with hematopoietic stem cells from volunteer donors selected from the international registry. The development of European national registries covering populations with different HLA haplotype frequencies is essential for optimizing donor search algorithms and providing the best chance for European patients to find a fully compatible donor.

c) 2014 S. Karger AG, Basel

\section{Introduction}

Human leucocyte antigens (HLA) are encoded in the major histocompatibility complex (MHC) and represent the most polymorphic genes in all human populations. Although originally defined as blood groups present on leucocytes, HLA molecules are expressed on the surface of virtually all nucleated cells. Their biological role is to present peptides derived from pathogens or altered selfproteins to the immune system of the host. A cellular and humoral adaptive immune response is initiated after the recognition of HLA-peptide complexes by specific recep-

\section{KARGER}

E-Mail karger@karger.com

www.karger.com/hhe (c) 2014 S. Karger AG, Base

0001-5652/14/0764-0178\$39.50/0
Dr. J.-M. Tiercy

National Reference Laboratory for Histocompatibility

Department of Genetics and Laboratory Medicine, Geneva University Hospital

4 rue Gabrielle-Perret-Gentil, CH-1211 Geneva 14 (Switzerland)

e-Mail jean-marie.tiercy@ unige.ch 
tors on T lymphocytes. This defence mechanism is highly efficient in fighting against infections but constitutes a major barrier to transplantation because $\mathrm{T}$ and $\mathrm{B}$ cells are capable to recognize allogeneic (i.e. incompatible) HLA molecules and develop a cellular and/or humoral response to mismatched HLA antigens. Host-pathogen interactions have contributed to the selection of HLA alleles at the population level. The extreme diversity of the HLA system has a major impact on the likelihood to find HLAcompatible donors in organ and hematopoietic stem cell transplantation (HSCT). The genetic variability within a population and also between different populations has therefore to be considered in organ exchange programs and in unrelated hematopoietic stem cell (HSC) donor search algorithms.

\section{HLA Polymorphism}

The human MHC on the short arm of chromosome 6 comprises HLA class I (A, B, C) and class II genes (DRA, DRB1, DRB3, DRB4, DRB5, DQA1, DQB1, DPA1, DPB1; fig. 1) [1]. HLA loci encode cell surface HLA molecules (fig. 1) which are characterized by a high degree of polymorphism. In clinical laboratories, about 100 different HLA serotypes (A, B, C, DR, DQ) can be defined on peripheral blood lymphocytes using a complement-dependent cytotoxicity assay with HLA-specific alloantisera. Since the cloning and sequencing of the first HLA class I (A, B) and II genes (DRA/DRB1) in the early 1980s, the number of new HLA variants has increased continuously. Virtually all serotypes are now subdivided into several alleles ( 2 to $>400$ ) leading to more than 9,000 different alleles in the worldwide populations, each assigned a given name by the WHO HLA Nomenclature Committee [2] (www.ebi.ac.uk/ipd/imgt/hla). Although most of the polymorphisms are located in the exons encoding the very distal part of HLA molecules ( $\alpha 1 / \alpha 2$ domains for class I antigens and $\alpha 1 / \beta 1$ domains for class II antigens; fig. 1) forming the peptide-binding cleft, variations are also located elsewhere in the genes. About $25 \%$ of all HLA class I and II alleles differ by silent substitutions, and 3\% are characterized by mutations in coding or non-coding regions that lead to a lack of cell surface expression (null alleles; fig. 1).

The HLA alleles and haplotypes present large variations in frequencies within the worldwide populations [3-6]. Even within a given country, regional differences can be detected $[7,8]$. Because of the enormous diversity of allelic combinations, no more than 20 HLA-A,B,DRB1

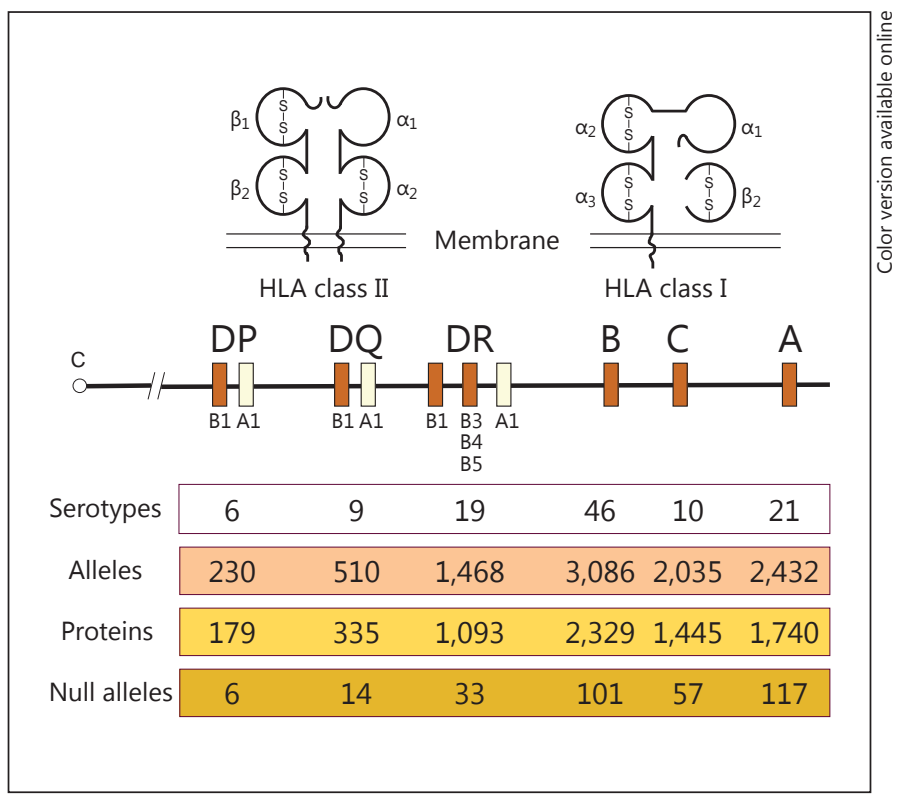

Fig. 1. Schematic map of the 4-Mbp human MHC and structure of cell surface HLA class I and II antigens. HLA class I are composed by a heavy chain encoded in the MHC with 3 domains ( $\alpha 1 / \alpha 2 / \alpha 3)$ combined with $\beta 2$-microglobulin; the $\alpha 1 / \alpha 2$ domains form the peptide-binding site and are highly polymorphic. HLA class II antigens are heterodimers of $\alpha / \beta$ chains both encoded in the MHC. The most distal domains $\alpha 1 / \beta 1$ form the peptide-binding site, and the polymorphism is essentially located in the $\beta 1$ domain. In the 4 rows below the map the total numbers of serotypes, alleles (Database version 3.14.0), proteins and null alleles (alleles with no cell surface expression as detected by serological methods) are indicated for each locus, respectively. The DR serotypes include the antigens encoded by the DRA/DRB1, DRA/DRB3, DRA/DRB4 and DRA/DRB5 genes.

haplotypes occur at a frequency of more than 0.01 [4]. A recent international survey of sequenced alleles allowed to estimate that $14.3 \%$ of all HLA class I and II alleles (IMGT/HLA Database release 3.9.0) occurred at a frequency of more than 0.0001 or were identified in $\geq 5$ unrelated individuals or in $\geq 3$ individuals with a specific haplotype [9]. This means that the large majority of alleles are found at extremely low frequencies and should not significantly impact patient-donor matching in clinical transplantation.

Combinations of HLA antigens encoded by genes on the same chromosome are referred to as HLA haplotypes. A Mendelian segregation of HLA-A,B,DRB1 haplotypes is illustrated in figure 2 . The probability that a sibling donor shares the same two haplotypes with a patient is $25 \%$. The probability of sharing only one haplotype is $50 \%$. In that case, the sibling is said to be haploidentical and, by 


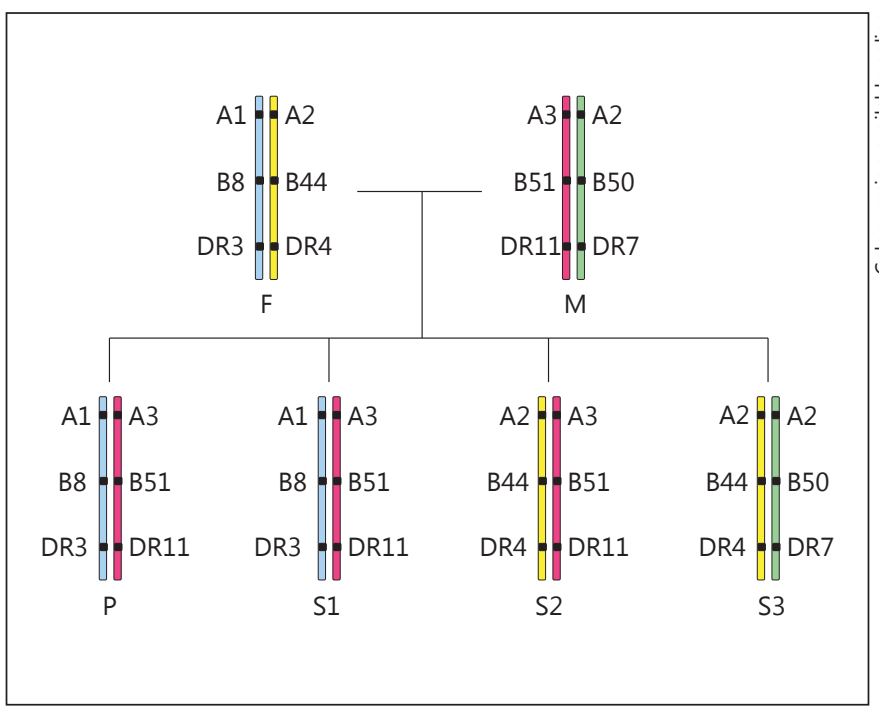

Fig. 2. Mendelian inheritance of HLA-A,B,DRB1 haplotypes in a family study. A patient and a sibling donor have a $25 \%$ chance to be genotypically HLA identical, i.e. sharing the same 2 haplotypes, and a $50 \%$ chance of being HLA haploidentical, i.e. sharing one haplotype. In most cases the segregation of the haplotypes can be defined unambiguously on the basis of HLA-A,B,DRB1 typing. Because HLA-C is located between the A and $B$ loci and because the DRB1 and DQB1 loci are closely linked, A,B,DRB1 matching implies C and DQB1 matching. HLA-DPB1 matching is expected in about $98 \%$ of the cases, taking into account a $1-2 \%$ recombination rate between $\mathrm{DQB} 1$ and $\mathrm{DPB} 1$ loci. $\mathrm{F}=$ Father; $\mathrm{M}=$ mother; $\mathrm{P}=$ patient $\mathrm{S} 1=\mathrm{HLA}$-identical sibling $1 ; \mathrm{S} 2=$ HLA-haploidentical sibling 2; S3 = HLA-incompatible sibling 3. For simplification, the genotypes are indicated using the serologic nomenclature.

definition, each parent is also haploidentical to the patient. In the example shown in figure 2, segregation of the haplotypes can be defined on the basis of HLA-A,B,DRB1 low-resolution typing because heterozygosity at each locus allows to assign the inheritance of the alleles without ambiguity. This is not possible in case of homozygosity, or when unrelated donors are analysed (see below). In those situations, high-resolution typing is required to ascertain full compatibility between a patient and a potential (related or unrelated) donor.

In clinical transplantation, the degree of 'compatibility' depends on the method used and on the number of HLA loci tested. Since most HLA serotypes are subdivided into many different alleles, two unrelated individuals can be compatible at the serotype level (CDC typing), but mismatched at the allele level (DNA typing), i.e. patient and donor are both HLA-A2, but the patient is $A^{*} 02: 01$ and the donor $A^{*} 02: 06$. The analysis of the serotype A2 (by serology) or of the allele group $A^{*} 02$ (by
DNA typing) is usually referred to as 'low-resolution typing' [10]. The assignment of the $A^{*} 02: 01$ and $A^{*} 02: 06$ alleles is commonly referred to as 'high-resolution typing' [10] and is mandatory in HSCT, at least for unrelated donor matching, because alloreactive $\mathrm{T}$ cells are even able to recognize mismatched alleles which differ in a single amino acid.

The situation is different for organ transplantation. Until recently, HLA matching has been mainly performed on the basis of low-resolution typing since patients receive life-long immunosuppression, which diminishes the role of alloreactive $\mathrm{T}$ cells. Furthermore, the potential donor pool is too small to aim at compatibility at the high-resolution level. Currently, most rejectionassociated complications after solid organ transplantation are due to the formation of HLA antibodies [11]. Preventing the formation of antibodies requires a different matching strategy. Most HLA alleles within a given serotype share immunogenic epitopes [12], and intelligent low-resolution matching can already prevent the formation of antibodies to some degree. However, recent data suggest that donor selection for highly sensitized patients and the prevention of antibody formation can only take place if both donor and recipient are typed at the high-resolution level [13].

\section{Anti-HLA Antibody Response}

HLA antigens were originally identified with antibodies induced by blood transfusion [14] or pregnancy $[15,16]$. Another source of immunization is transplantation. For the formation of HLA antibodies, a confrontation with foreign HLA antigens is necessary, this is in contrast to $\mathrm{ABO}$ antibodies that are naturally present. In the past, when HLA antigens were identified serologically, the dogma was that a confrontation with foreign HLA antigens will lead to the formation of antibodies, although the exact epitopes recognized by the antibodies were unknown. Molecular and high-resolution HLA typing has led to the exact definition of the amino-acid sequence of all HLA alleles and to the identification of the important antibody epitopes on the different HLA molecules [17]. These epitopes are not exclusive for one particular HLA allele, but HLA alleles may share epitopes. As patients do not produce antibodies to epitopes present on their own HLA antigens, one can even identify foreign HLA alleles that only carry epitopes shared with the patient's own HLA antigens and which will not induce antibodies [18]. 


\section{Anti-HLA Alloreactivity}

Alloreactive T cells mediate graft rejection after solid organ transplantation (host anti-donor response), and graft-versus-host disease (donor anti-host response) in HSCT. Such alloresponses can be based on either a direct allorecognition of the incompatible HLA antigen through peptide-dependent structural mimicry [19], or an indirect allorecognition of donor HLA peptides presented by recipient HLA molecules [20]. The reactivity of T cells with incompatible HLA molecules is unexpected as T cells are educated to recognize viral and bacterial peptides in the context of self HLA. Recent studies have shown that reactivity with incompatible HLA is based on crossreactivity of $\mathrm{T}$ cells meant to recognize viral peptides in self HLA [21, 22]. As a consequence, a patient, who has never been confronted with foreign HLA but has experienced several infections, can have memory $\mathrm{T}$ cells to foreign HLA antigens on a graft affecting transplant outcome.

\section{Impact of HLA Diversity on Organ Transplantation}

Already in the early days of renal transplantation, it became clear that the HLA antigens are strong transplantation antigens [23]. The best transplant results were obtained when donor and recipient were HLA identical, and the more HLA mismatches, the poorer the results. The introduction of very potent immunosuppressive drugs has diminished the impact of HLA matching on graft survival, although the beneficial effect still exists [24]. A more important reason to match for HLA in solid organ transplantation is to prevent the formation of antibodies. The presence of donor-specific HLA antibodies before transplantation leads to a hyperacute rejection [25]. This complication is prevented by a serological crossmatch and the exclusion of donors towards whom the patient has formed specific antibodies [26]. However, HLA antibodies may also be formed after transplantation and are associated with acute and chronic graft rejection [27]. The more foreign antibody epitopes there are present on the donor organ, the higher the chance that a patient will form antibodies [28]. Especially for children, who often need a retransplantation, this is a potential problem as the presence of many HLA antibodies will prevent their retransplantation due to positive crossmatches [29]. A computer algorithm developed by Rene Duquesnoy, called HLAMatchmaker, can determine the immunogenicity of an HLA mismatch by comparing the epitopes on

HLA Diversity in Organ and Stem Cell Transplantation
Single donor mismatch HLA B18, while patient is HLA B7:

HLA B18 has 11 potential epitopes not present on HLA B7

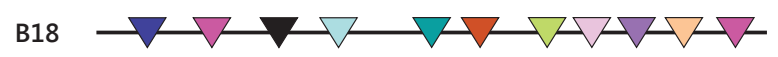

Patient HLA:

B7

B52

A33

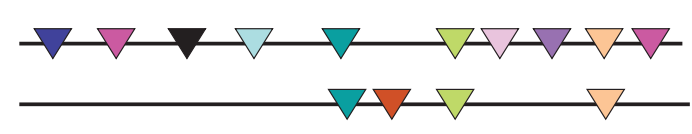

Potential epitopes on HLA B18 are shared by patients own HLA antigens (B52 and A33)

Fig. 3. Principle of the HLAMatchmaker approach. A donor is HLA-B18, while the patient is HLA-B7. All other HLA alleles are shared between donor and recipient. HLA-B18 has 11 potential antibody epitopes, which are not present on the patient's HLA-B7. However, these 11 potential antibody epitopes are present/shared on the patient's other HLA antigens (B52 and A33). As a patient is not supposed to produce antibodies to self-epitopes, HLA-B18 can be considered an acceptable HLA mismatch for this particular patient.

foreign HLA antigens with those on the patient's own HLA antigens [30]. This tool is very useful for the selection of not very immunogenic HLA mismatches for children.

Highly sensitized patients, who have formed many HLA antibodies directed against many different HLA antigens, are very difficult to transplant as crossmatches with a potential donor are very often positive. For this reason these patients tend to accumulate on the transplantation waiting lists. A special strategy has been shown to be instrumental in facilitating transplantation of this difficult patient group [31]. It gives priority to these patients, when donors become available towards whom the patient do not produce antibodies, the so-called 'acceptable mismatch program' [31]. The HLAMatchmaker algorithm can help here, too, to define HLA antigens towards which a patient will not make antibodies, as illustrated in figure 3.

\section{Impact of HLA Diversity on Donor Selection for HSCT}

Allogenic HSCT is a well-recognized therapy for haematological malignancies and inborn errors of the immune system [32]. HLA polymorphism represents a ma- 
jor barrier to transplantation, because HLA incompatibilities at the allele level (down to a difference of one amino acid) can be efficiently recognized by alloreactive $\mathrm{T}$ lymphocytes. Therefore, the best HSC donor is a sibling who has inherited the same paternal and maternal HLA haplotypes as the patient. The probability to find a genotypically identical sibling donor is $25 \%$, and it increases with the number of siblings: i.e. the probability is $43.7 \%$ with 2 siblings, $57.8 \%$ with 3 siblings (see fig. 2 ), or $68.4 \%$ with 4 siblings. However, because of a lack of matched sibling donors, at least in West-European populations, an increasing number of patients can have access to HSCT thanks to a worldwide registry of volunteer donors (BMDW: Bone Marrow Donor Worldwide). These donors are HLA typed, mostly at the low/intermediate-resolution level for HLA-A/B/(C)/DRB1/(DQB1), and they can be selected from the database on the basis of the best matching rate with a given patient. Searches are usually based on HLA allele compatibility for the HLAA,B,C,DRB1,DQB1 loci, a so-called '10/10 match' [33, 34]. Any mismatch results in a 9/10-matched donor, 2 mismatches in a 8/10-matched donor, etc. Because of the extensive HLA polymorphism, a 10/10-matched donor can only be identified for about $50 \%$ of all patients, and a 9/10-matched donor for an additional $20-30 \%$ of all patients [35-38] (table 1).

The implementation of recipient and donor HLA high-resolution genotyping in the clinical practice has clearly improved the success of transplantation through a better matching $[33,34,39]$, but it has also resulted in more complex search algorithms. Several studies have shown that patients' allele and haplotype frequencies have a strong impact on the chance to identify a compatible donor [37, 38, 40, 41]. Despite the fact that more than 20 million donors are now registered in BMDW, for about $5 \%$ of the patients there is no single potential donor in the database, either because the patient's HLA$\mathrm{A}, \mathrm{B}, \mathrm{DRB} 1$ phenotype is absent in the database or because available donors typed at the intermediate/high-resolution level have allele mismatches. As summarized in table 1 , about $70 \%$ of all patients, mainly of European ancestry, may benefit from a 10/10- or 9/10-matched donor on the basis of high-resolution typing of potential donors selected from the international registry. The large registries with several million donors (USA, Germany) allow the identification of a compatible donor for a majority of patients of European ancestry. However, a number of patients rely on smaller registries to find a matched donor, because specific low-frequency HLA haplotypes present a more restricted geographical distribution (see below).
Table 1. Patient/donor-matching probabilities in different European countries

\begin{tabular}{lll}
\hline $\begin{array}{l}\text { Patients with a 9- } \\
10 / 10 \text {-matched donor, \% }\end{array}$ & $\begin{array}{l}\text { Time frame, } \\
\text { months }^{\mathrm{d}}\end{array}$ & Reference \\
\hline $69 \%^{\mathrm{a}}$ & 2.5 & {$[35]$} \\
$72 \%$ & $2.5-3.2$ & {$[42]$} \\
$61.1 \% \mathrm{~b}$ & $<1 / 1.5 / 16^{\mathrm{e}}$ & {$[40]$} \\
$78.3 \%^{\mathrm{c}}$ & 1.84 & {$[43]$} \\
$81.8 \%$ & $1.8 / 2.4 / 2.8^{\mathrm{e}}$ & {$[37]$} \\
$79 \%$ & n.a. & {$[38]$} \\
\hline
\end{tabular}

${ }^{\text {a }}<9 / 10$ in $13 \%$ of all patients.

${ }^{\mathrm{b}}$ Corresponds to 10/10-matched donors only.

${ }^{c}$ Exceptionally 8/10-matched donors.

d Time from start of the search until the identification of a 910/10-matched donor.

e Search duration for patients with high-/intermediate-/lowfrequency HLA haplotypes.

Table 2. Relative number of $C^{*} 02: 02$-positive donors among 226 donors with the $A^{*}$ 03:01-B*51:01-DRB1*04:01 haplotype

\begin{tabular}{lcll}
\hline Registry & Donors $^{\mathrm{a}}$ & $\begin{array}{l}\text { Relative } \\
\text { occurrence }^{\mathrm{b}}\end{array}$ & $\begin{array}{l}\mathrm{C}^{*} \text { 02:02-positive } \\
\text { donors, n (\%) }\end{array}$ \\
\hline Germany & 90 & $1.84 \times 10^{-5}$ & $9(10 \%)$ \\
USA & 65 & $0.88 \times 10^{-5}$ & $4(6 \%)$ \\
The UK & 63 & $7.19 \times 10^{-5}$ & 0 \\
The Netherlands & 5 & $11.9 \times 10^{-5}$ & $1(20 \%)$ \\
Portugal & 3 & $0.94 \times 10^{-5}$ & $2(66 \%)$ \\
\hline
\end{tabular}

${ }^{a}$ Number of donors with the phenotypes A3-B51-DR4/A1B8-DR3, A3-B51-DR4/A3-B7-DR15 and A3-B51-DR4/A29-B44DR7 with available HLA-C-typing results.

b Relative occurrence of the 3 phenotypes A1/3,B8/51,DR3/4, A3/-,B7/51,DR15/4 and A3/29,B51/44,DR4/7 with available HLA-C types in each of the 5 national registries.

\section{HLA Diversity and Search Algorithm}

What is the impact of HLA diversity in different European populations on donor searches? European stem cell donor registries have now more than 8 million HLAtyped donors, in the worldwide database of 21 million donors, distributed in 69 different national registries from 50 countries, characterized by their widely differing sizes (www.bmdw.org):

- registries with less than 100,000 donors: such as the Danish $(28,000)$, Dutch $(44,000)$, Swiss $(48,000)$, or Austrian $(63,000)$ registries, 
Table 3. Relative frequencies of potential donors in two search categories

\begin{tabular}{lcc}
\hline Registry & $\begin{array}{l}1-15 \\
\text { donors }\end{array}$ & $\begin{array}{l}16-150 \\
\text { donors }\end{array}$ \\
\hline USA & 29 & 24 \\
Germany & 19 & 23 \\
Great Britain/Ireland & 2 & 4.5 \\
Brazil & 19 & 20 \\
Australia/Canada & 2 & 3.5 \\
Portugal/Spain/Italy & $\mathbf{1 3}$ & 7 \\
Belgium/France/Switzerland/ & & \\
$\quad$ the Netherlands & 2 & 2.5 \\
Sweden/Denmark & $\mathbf{3}$ & 1 \\
Poland/Slovenia/Slovakia/Croatia & $\mathbf{6}$ & 4.5 \\
\hline
\end{tabular}

The results are the average ratio (in percent) of potential donors from any given national registry over the total number of potentially matched donors available for each of the 2 groups of patients ( $n=168$ for the searches with $1-15$ donors, $n=2,594$ for the searches with 16-150 donors).

All searches were run in 2012. The respective numbers of donors from other European, Central/South-American, and Asian registries are too small to be meaningful and are therefore not represented. See text for more details.

Bold values show higher relative frequencies of donors.

- registries with between 100,000 and 500,000 donors: such as the Portugese $(336,000)$, French $(220,000)$, or Italian $(340,000)$ registries, and

- registries with more than 500,000 donors: such as the Anthony Nolan (UK; 500,000), German (5.1 million), or NMDP (National Marrow Donor Program, USA; 7.3 million) registries.

Because of the geographical differences in HLA haplotype frequencies and in the total number of registered donors per country, the probability to find a suitable donor may vary greatly depending on which registry is interrogated. The impact of HLA diversity in different populations can be illustrated with the following clinical case: the search for a patient with the haplotypes $A^{*} 29: 02-B^{*} 44: 03$ $C^{*} 16: 01-D R B 1{ }^{*} 07: 01$ and $A^{*} 03: 01-B^{*} 51: 01-C^{*} 02: 02$ $\mathrm{DRB} 1 * 04: 01$ led to the identification of 37 donors with a single HLA-C mismatch (9/10 match), whereas only 3 HLA-C-matched donors (i.e. potential 10/10 matches) were identified in the US, German and French registries, respectively. Of the 31 donors from the US and UK registries who were registered with HLA-C types, only 1 (3.2\%) was compatible, whereas 2 of the 6 (33\%) HLA-typed donors from the German and French registries were compatible (data not shown). This suggests that the $B^{*} 51: 01$ -

HLA Diversity in Organ and Stem Cell

Transplantation
$\mathrm{C}^{*} 02: 02$ association is rare in populations of North-European origin. This observation was further supported by the analysis of the same $A^{*} 03: 01-B^{*} 51: 01-C^{*} 02: 02$ DRB $1 * 04: 01$ haplotype when combined with any of the 3 most frequent haplotypes (A1-B8-DR3, A3-B7-DR15 and A29-B44-DR7). An interrogation of the BMDW registry showed that of 226 donors only 16 donors (7\%) typed as $B^{*}$ 51:01-C*02:02 (table 2). Again 100\% of the 63 donors from the UK and $94 \%$ from the US registries were C-incompatible, whereas 2 out of 3 donors from the Portuguese registry were compatible for HLA-C (table 2).

In order to indirectly evaluate the impact of HLA diversity in different European populations, we determined the ratio of potential donors originating from 'small' or 'intermediate-sized' European registries compared to donors from large registries (USA, Germany, the UK). We thus compared the origin (national registry) of potential donors for the 2 following categories of patients: those patients with more common haplotypes, i.e. with more than 15 potential donors in the BMDW (40 searches), and those patients with less than 16 donors (28 searches). As shown in table 3 (numbers in bold), a trend towards a higher relative frequency of donors from South-European (Portugal, Spain, Italy), North-European (Sweden, Denmark) and East-European (Poland, Slovenia, Croatia, Slovakia) registries is observed. Interestingly, the relative percentage of BMDW-available donors from the British, Irish, German, Australian or Canadian registries was lower in searches for patients with low-frequency haplotypes.

\section{Discussion}

Since the use of unrelated HSC donors is deemed to grow, the efficiency of a search algorithm will benefit from a larger diversity of HLA haplotypes represented in the database, and of a higher quality of the HLA-typing data of the newly registered donors. A few registries are now providing sequencing data at HLAA,B,C,DRB1,DQB1 loci. A better knowledge of HLA allele/haplotype frequencies in different populations will certainly allow to better delineate search strategy and thus focus donor selection on specific donor population groups, whenever donors are not typed at a high-resolution level for all HLA loci. Particularly challenging are searches for patients of non-European ancestry because of the underrepresentation of donors from other ethnic groups in the BMDW registry. This problem is underlined by a recent study reporting a $33 \%$ success rate in donor identification (7-8/8 match) for patients of African 
ancestry, as compared to $76 \%$ for patients of European ancestry [44]. The increasing heterogeneity of the European populations, with patients of African, Asian, SouthAmerican, or mixed ancestry, calls for an increase in donor recruitment among these populations.

For those patients who cannot benefit of a fully matched donor, the challenge remains to identify more permissive or less immunogenic HLA mismatches, which are associated with less clinical complications. An alternative for these patients is HSCT from haploidentical donors or from cord blood units.

As a consequence of the extreme diversity of HLAhaplotypic associations in many populations, it appears of primary importance to support donor recruitment in all European countries. Even though the 2 largest registries account for more than 70\% of all donors in Europe, they may not cover sufficient HLA diversity to provide matched donors, particularly for patients of South- and East-European ancestry. HLA diversity does not only mean the inclusion of new A,B,DRB1 phenotypes in the database, but also extending the allelic variability within already existing A,B,DRB1 phenotypes. The development of the so-called 'small' registries should be a priority, but should not be at the expenses of HLA-typing quality.

The situation is different in organ transplantation, where a worldwide search for HLA-compatible donors is not feasible for logistic reasons. Nevertheless, the best results here are also obtained with fully HLA-matched donors, although the outcome of HLA-mismatched transplants is still very good due to efficient immunosuppressive medication. The main reason for graft failure in renal transplantation is the (de novo) formation of donor-specific HLA antibodies [27].

If the induction of HLA antibodies can be prevented, the risk to develop acute or chronic graft rejection will diminish. Furthermore, the chance that a patient will receive a retransplantation depends on the degree of sensi- tization after the rejection of a previous transplant. Preventing the formation of HLA antibodies will be beneficial for patients in need for a retransplantation as is often the case in paediatric patients.

For these reasons, the strategy in organ transplantation will be more focussed on matching at the level of antibody epitopes [45]. Individual HLA alleles express different antibody epitopes, but these epitopes are shared with some other HLA alleles. This information together with the fact that a patient will not form antibodies to epitopes present on her/his own HLA molecules will be the basis of future matching strategies using algorithms like HLAMatchmaker. This will facilitate donor selection, as only 150-200 amino-acid variations within more than 5,000 HLA class I alleles are responsible for the induction of virtually all HLA antibodies. The current challenge is a clear definition of these crucial amino-acid variations associated with the induction of antibodies, and next the definition of the exact epitopes recognized by allo-antibodies in order to select the optimal donor for sensitized patients.

It has become clear in this review that the enormous polymorphism of HLA antigens, which is essential for our defence to viruses and bacteria, hampers the selection of an optimal donor for a patient in need for a transplantation. Knowledge of the exact amino-acid sequence of all HLA alleles, and especially the crucial positions for $\mathrm{T}$ cell and antibody recognition, and of the HLA-haplotype distribution in different populations all over the world will enable the selection of the best donor for a potential transplant recipient.

\section{Acknowledgements}

This work has been supported by grant No. 310030_146306 from the Swiss National Science Foundation and by the National Reference Laboratory for Histocompatibility Testing in the Netherlands.

\section{References}

Shiina T, Hosomichi K, Inoko H, Kulski JK: The HLA genomic loci map: expression, interaction, diversity and disease. J Hum Genet 2009;54:15-39.

-2 Marsh SG, Albert ED, Bodmer WF, Bontrop RE, Dupont B, Erlich HA, Fernandez-Vina M, Geraghty DE, Holdsworth R, Hurley CK, Lau M, Lee KW, Mach B, Maiers M, Mayr W, Müller CR, Parham P, Petersdorf EW, Sasazuki T, Strominger JL, Svejgaard A, Terasaki PI, Tiercy J-M, Trowsdale J: Nomenclature for factors of the HLA system, 2010. Tissue Antigens 2010;75:291-455.

\footnotetext{
3 Maiers M, Gragert L, Klitz W: High-resolution HLA alleles and haplotypes in the United States population. Hum Immunol 2007;68: 779-788.

-4 Eberhard HP, Feldmann U, Bochtler W, Baier D, Rutt C, Schmidt AH, Müller CR: Estimating unbiased haplotype frequencies from stem cell donor samples typed at heterogeneous resolutions: a practical study based on over 1 million German donors. Tissue Antigens 2010;76:352-361.
} 
5 Sanchez-Mazas A, Fernandez-Vina M, Middleton D, Hollenbach JA, Buhler S, Di D, Rajalingam R, Dugoujon JM, Mack SJ, Thorsby E: Immunogenetics as a tool in anthropological studies. Immunology 2011;133:143164.

-6 Fernandez-Vina M, Hollenbach JA, Lyke KE, Sztein MB, Klitz W, Cano P, Mack S, Single R, Brautbar C, Israel S, Raimondi E, Khoriaty E, Inati $\mathrm{A}$, Amdreani $\mathrm{M}$, Testi $\mathrm{M}$, Moraes $\mathrm{ME}$, Thomson G, Statsny P, Cao K: Tracking human migrations by the analysis of the distribution of HLA alleles, lineages and haplotypes in closed and open populations. Philos Trans R Soc Lond B Biol 2012;367:820-829.

-7 Schmidt AH, Solloch UV, Baier D, Stahr A, Wassmuth R, Ehninger G, Rutt C: Regional differences in HLA antigen and haplotype frequency distribution in Germany and their relevance to the optimization of hematopoietic stem cell donor recruitment. Tissue Antigens 2010;76:362-379.

8 Buhler S, Nunes JM, Nicoloso G, Tiercy JM, Sanchez-Mazas A: The heterogeneous genetic makeup of the Swiss population. PLoS One 2012; 7:e41400.

-9 Mack SJ, Cano P, Hollenbach JA, et al: Common and well-documented HLA alleles: 2012 update to the CWD catalogue. Tissue Antigens 2013;81:194-203.

10 Nunes E, Heslop H, Fernandez-Vina M, Taves C, Wagenknecht DR, Eisenbrey AB, Fischer G, Poulton K, Wacker K, Hurley CK, Noreen $\mathrm{H}$, Sacchi N: Definitions of histocompatibility typing terms. Blood 2011;118:e180-e183.

-11 Everly MJ, Rebellato LM, Haische CE, Ozawa M, Parker K, Briley KP, Catrou PG, Bolin P, Kendrick WT, Kendrick SA, Harland RC, Terasaki PI: Incidence and impact of de novo donor-specific alloantibody in primary renal allografts. Transplantation 2013;95:410-417.

-12 Duquesnoy RJ, Takemoto S, de Lange P, Doxiadis II, Schreuder GM, Persijn GG, Claas FH: HLAMatchmaker: a molecularly based algorithm for histocompatibility determination. III. Effect of matching at the HLA-A,B amino acid triplet level on kidney transplant survival. Transplantation 2003;75:884-889.

-13 Tait BD, Susal C, Gebel HM, Nickerson PW, Zachary AA, Claas FHJ, Reed EF, Bray RA, Campbell P, Chapman JR, Coates PT, Colvin RB, Cozzi E, Doxiadis II, Fuggle SV, Gill J, Glotz D, Lachman N, Mohanakumar T, Suciu-Foca N, Sumitran-Holgersson S, Tanabe K, Taylor CJ, Tyan DB, Webster A, Zeevi A, Opelz G: Consensus guidelines on testing and clinical management issues associated with HLA and non-HLA antibodies in transplantation. Transplantation 2013;95:19-47.

14 Dausset J: Leuco-agglutinins IV. Leuco-agglutinins and blood transfusion. Vox Sang 1954;4:190-194.

15 Van Rood JJ, Eernisse JG, Van Leeuwen A: Leucocyte antibodies in sera from pregnant women. Nature 1958;181:1735-1736.
Payne R, Rolfs MR: Fetomaternal leucocyte 1763.

17 Duquesnoy FJ, Marrari M: Correlation between Terasaki's HLA class I epitopes and HLAMatchmaker-defined eplets on HLA-A, $-\mathrm{B}$ and $-\mathrm{C}$ antigens. Tissue Antigens 2009;74: 117-133.

18 Duquesnoy RJ, Witvliet M, Doxiadis I, de Fijter H, Claas FHJ: HLAMatchmaker-based strategy to identify acceptable HLA class I mismatches for highly sensitized transplant candidates. Transpl Int 2004;17:22-30.

19 Macdonald WA, Chen Z, Gras S, Archbold JK, Tynan FE, Clements CS, Bharadwaj M, Kjer-Nielsen L, Saunders PM, Wilce MC, Crawford F, Stadinsky B, Jackson D, Brooks AG, Purcell AW, Kappler JW, Burrows SR, Rossjohn J, McCluskey J: T cell allorecognition via molecular mimicry. Immunity 2009; 31:897-908.

20 Gökmen MR, Lombardi G, Lechler RI: The importance of the indirect pathway of allorecognition in clinical transplantation. Curr Opin Immunol 2008;20:568-574.

-21 Amir A, D’Orsogna L, Roelen DL, van Loenen MM, Hagedoorn RS, de Boer R, van der Hoom MA, Kester MG, Doxiadis II, Flakenburg JH, Claas FH: Allo-HLA reactivity of virus-specific memory $\mathrm{T}$ cells is common. Blood 2010;115:146-157.

22 D’Orsogna LJ, Nguyen THO, Claas FHJ, Witt C, Mifsud NA: Endogenous-peptide-dependent alloreactivity: new scientific insights and clinical implications. Tissue Antigens 2013; 81:399-407.

23 Persijn GG, Gabb BW, van Leeuwen A, Nagtegaal A, Hoogeboom J, Van Rood JJ: Matching for HLA antigens of A,B and DR loci in renal transplantation by Eurotransplant. Lancet 1978;1:1278-1281.

24 Süsal C, Opelz G: Current role of human leukocyte antigen matching in kidney transplantation. Curr Opin Organ Transplant 2013;18: 438-444.

25 Kissmeyer-Nielsen F, Olsen S, Petersen VP, Fjeldborg O: Hyperacute rejection of kidney allografts associated with preexisting humoral antibodies against donor cells. Lancet 1966; 7465:662-665.

26 Patel R, Terasaki PI: Significance of a positive crossmatch in kidney transplantation. New Engl J Med 1969;280:735-739.

27 Lachmann N, Terasaki PI, Budde K, Liefeldt L, Kahl A, Reinke P, Pratschke J, Rudolph B, Schmidt D, Salama A, Schönemann C: Antihuman leukocyte antigen and donor-specific antibodies by luminex posttransplant serve as biomarkers of chronic rejection of renal allografts. Transplantation 2009;87:1505-1513.

28 Dankers M, Witvliet M, Roelen D, de Lange P, Korfage N, Persijn G, Duquesnoy R, Doxiadis II, Claas FH: The number of amino acid differences between patient and donor is predictive for antibody reactivity against mismatched HLA antigens. Transplantation 2004;77:1236-1239.
29 Gralla J, Tong S, Wiseman AC: The impact of human leucocyte antigen mismatching on sensitization rates and subsequent retransplantation after first graft failure in paediatric renal transplants recipients. Transplantation 2013;95:1218-1224.

30 Duquesnoy RJ: HLAMatchmaker: a molecularly based algorithm for histocompatibility determination. I. Description of the algorithm. Hum Immunol 2002;63:339-352.

31 Claas FHJ, Rahmel A, Doxiadis II: Enhanced kidney allocation to highly sensitized patients by the acceptable mismatch program. Transplantation 2009;88:447-452.

32 Copelan EA: Hematopoietic stem-cell transplantation. New Engl J Med 2006;354:18131826.

33 Petersdorf EW: Optimal HLA matching in hematopoietic cell transplantation. Curr Opin Immunol 2008;20:588-593.

-34 Shaw B, Arguello R, Garcia-Sepulveda CA, Madrigal JA: The impact of HLA genotyping on survival following unrelated donor haematopoietic stem cell transplantation. Br J Hematol 2010;150:251-258.

35 Heemskerk MB, van Walraven SM, Cornelissen JJ, Barge RM, Bredius RG, Egeler RM, Lie JL, Révész T, Sintnicolaas K, Wulffraat NM, Donker AE, Hoogerbrugge PM, van Rood JJ, Claas FH, Oudshoorn M: How to improve the search for an unrelated haematopoietic stem cell donor. Faster is better than more! Bone Marrow Transplant 2005;35:645-652.

- 36 Tiercy JM, Nicoloso G, Passweg J, Schanz U, Seger R, Chalandon Y, Heim D, Güngör T, Schneider P, Schwabe R, Gratwohl A: The probability to identify a 10/10 HLA allelematched unrelated donor is highly predictable. Bone Marrow Transplant 2007;40:515522.

37 Tiercy JM: Unrelated hematopoietic stem cell donor matching probability and search algorithm. Bone Marrow Res 2012;2012:695018.

38 Jöris MM, Lankester AC, von dem Borne PA, Kuball J, Bierings M, Cornelissen JJ, Groenendijk-Sijnke ME, van der Holt B, Haasnoot GW, van der Zanden HG, van Walraven SM, van Rood JJ, Claas FH, Oudshoorn M: The impact of frequent HLA haplotypes in high linkage disequilibrium on donor search and clinical outcome after unrelated hematopoietic SCT. Bone Marrow Transplant 2012:48: 483-490.

39 Petersdorf EW: The major histocompatibility complex: a model for understanding graftversus-host disease. Blood 2013;122:18631872.

40 Hirv K, Bloch K, Fischer M, Einsiedler B, Schrezenmeier H, Mytilineos J: Prediction of duration and success rate of unrelated hematopoietic stem cell donor searches based on the patient's HLA-DRB1 allele and DRB1DQB1 haplotype frequencies. Bone Marrow Transplant 2009;44:433-440.
HLA Diversity in Organ and Stem Cell Transplantation
Hum Hered 2013;76:178-186 DOI: $10.1159 / 000358798$ 
41 Pédron B, Guérin-El Khourouj V, Dalle JH, Ouachée-Chardin M, Yakouben K, Corroyez F, Auvrignon A, Petit A, Landman-Parker J, Leverger G, Baruchel A, Sterkers G: Contribution of HLA-A/B/C/DRB1/DQB1 common haplotypes to donor search outcome in unrelated hematopoietic stem cell transplantation. Biol Blood Marrow Transplant 2011;17: 1612-1618.

42 Querol S, Mufti GJ, Marsh SGE, Pagliuca A, Little AM, Shaw BE, Jeffery R, Garcia J, Goldman JM, Madrigal JA: Cord blood stem cells for hematopoietic stem cell transplantation in the UK: how big should the bank be? Hematologica 2009;94:536-541.
3 Rosenmayr A, Pointner-Prager M, Winkler M, Mitterschiffhaler A, Pelzmann B, Bozic L, Pichler SK, Tüchler H, Fae I, Fischer G: The Austrian bone marrow donor registry: providing patients in Austria with unrelated donors for transplant - a worldwide cooperation. Transfus Med Hemother 2012;38:292299.
4 Pidala J, Kim J, Schell M, Lee SJ, Hillgruber R, Nye V, Ayala E, Alsina M, Betts B, Bookout R, Fernandez HF, Field T, Locke FL, Nishihori T, Ochoa JL, Perez L, Pekins J, Shapiro J, Tate C, Tomblyn M, Anasetti C: Race/ethnicity affects the probability of finding an HLA-A, -B, $-C$ and -DRB1 allele-matched unrelated donor and likelihood of subsequent transplant utilization. Bone Marrow Transplant 2013;48: 346-350.

45 Tambur A, Claas FHJ: Towards HLA epitope matching in clinical transplantation. Am J Transplant 2013;13:59-60. 